on how Monnett awarded the research contract. This includes questions over whether Monnett complied with the Federal Acquisition Regulation, which is intended to ensure fair competition for US government contracts. The OIG adds that the inquiry is not criminal in nature, as the Department of Justice has already considered the case and declined to prosecute. Ruch says that Monnett's handling of the contract was transparent to his supervisors, and that his technical role meant he was not responsible for compliance with the regulation.

The project, begun in 2005, involves putting radio collars on polar bears found on the Canadian side of the Beaufort Sea, and tracking their position by satellite over several seasons. The study is funded by various sources, including the BOEMRE and the Canadian government. But on 13 July, the BOEMRE told scientists on the project to stop their work. The project's principal investigator, Andrew Derocher, a biologist at the University of Alberta in Edmonton, Canada, says he had no idea why. "To begin with, I thought it was related to budgetary issues in the United States. I've never seen anything like this in my life," he says.

Derocher says that data should continue to come in from collars until 2013, but the 'stop work' order may mean that he is unable to document his findings in a final report to the agency. Among those findings is that 2-4-year old polar bears tend not to stray far from their home range - the first time this age group has been tracked. This would mean that in the event of a large oil spill, bears that died from oil exposure would not be replaced quickly by bears from surrounding areas, says Derocher.

Drowned polar bears have not been reported by other scientists, but the hypothesis that a long search for sea ice makes it more likely that bears will get caught in stormy weather and drown is regarded as plausible. In January, scientists led by George Durner at the US Geological Survey in Anchorage, Alaska, reported the fate of an adult female bear as she swam more than 600 kilometres before reaching ice (G. M. Durner et al. Polar Biol. 34, 975-984; 2011). When the researchers caught up with the animal, she had lost $22 \%$ of her body mass and her year-old cub.

This finding, corroborated by other studies, suggests that the major impact of receding sea ice on the bears is nutritional stress caused by a reduction of their hunting range, says Steven Amstrup, chief scientist at the campaigning organization Polar Bears International, headquartered in Bozeman, Montana, and a co-author of the study. But the observation that drowning can occur is important, he adds. "If this investigation is not about those observations then the BOEMRE owes it to him and to the public to say clearly what it is about." -

\title{
Conflict disclosure plan dropped
}

\section{The NIH will not require universities to create websites detailing researchers' financial ties.}

\section{BY MEREDITH WADMAN}

$\mathrm{F}$ rancis Collins hailed it as a "new era of clarity and transparency in the management of financial conflicts of interest" (S. J. Rockey and F. S. Collins J. Am. Med. Assoc. 303, 2400-2402; 2010). But the director of the US National Institutes of Health (NIH) may have spoken too soon when he described a new rule, proposed last year, that would require universities and medical schools to publicly disclose online any financial arrangements that they believe could unduly influence the work of their NIH-funded researchers.

Nature has learned that a cornerstone of that transparency drive - a series of publicly accessible websites detailing such financial conflicts - has now been dropped. "They have pulled the rug out from under this," says Sidney Wolfe, director of the Health Research Group at Public Citizen, a consumer-protection organization based in Washington DC. "It greatly diminishes the amount of vigilance that the public can exercise over financially conflicted research being funded by the NIH." It will also make it more difficult for "scholars to study the effects of conflicts of interest in universities", adds Sheldon Krimsky, who studies science ethics at Tufts University School of Medicine in Boston, Massachusetts.

The NIH's parent agency, the Department of Health and Human Services (DHHS), proposed the new rule in May 2010, after congressional and media investigations revealed that prominent NIH grant recipients had failed to tell their universities or medical schools about lucrative payments from companies that may have influenced their government-funded research. The DHHS called the proposed websites "an important and significant new requirement to... underscore our commitment to fostering transparency, accountability, and public trust". Under the proposal, institutions with NIH-funded researchers would determine, grant by grant, if any financial conflicts existed for senior scientists on the grant. For example, these would include receiving consultancy fees, or holding shares in a company, "that could directly and significantly affect the design, conduct, or reporting" of the research. The institutions would post the details online, where they would stay for at least five years.
But a government official with knowledge of the ongoing negotiations on the rule says that the institutions will now be allowed to choose how to disclose this information, and will not be obliged to post it online. This is likely to make it much harder for members of the public to find these details, says Ned Feder, a senior staff scientist with the Project on Government Oversight. The watchdog group, based in Washington DC, wrote last month to the White House Office of Management and Budget (OMB) urging that the website requirement be protected. The OMB must sign off on the finalized form of the rule before it is published.

The OMB is also charged with enforcing an executive order issued by President Barack Obama in January. It requires government agencies to consider the costs of new regulations, and to tailor them to minimize cost and bureaucratic burden. "The websites don't appear out $\begin{array}{ll}\text { "The websites } & \text { of nowhere," says } \\ \text { don't appeather Pierce, senior } \\ \text { of nowhere." } & \begin{array}{l}\text { director of science pol- } \\ \text { icy at the Association } \\ \text { of American Medical }\end{array}\end{array}$ Colleges (AAMC) in Washington DC. They would "require employees to not only create the website but to pull the information, review it, and make sure it is up to date and accurate".

That is not the only objection from the powerful academic lobbies. During the public comment period last summer, the Association of American Universities and the AAMC submitted a joint statement saying: "There are serious and reasonable concerns among our members that the Web posting will be of little practical value to the public and, without context for the information, could lead to confusion rather than clarity regarding financial conflicts of interest and how they are managed."

The two groups note that the Physician Payment Sunshine Act, a new law requiring drug firms to disclose their payments to physicians, requires the DHHS secretary to create a publicly available online database listing these payments. The groups suggest that the same model could work to publicize the financial conflicts of NIH-funded researchers.

Although the final rule is expected to be published soon, it is already long overdue. In May 2010, Collins said that it would be finalized by the end of that year. 